\title{
Impactos jurídicos do conceito de empreendedorismo no grau de concentração regulatória normativa no setor de telecomunicações: o caso Actium*
}

Legal impacts of the concept of entrepreneurship on the level of normative regulatory concentration in the telecommunication sector: the Actium case

Submetido(submitted): 11 de janeiro de 2010

Parecer(revised): 19 de fevereiro de 2010

André Moura Gomes **

Aceito(accepted): 5 de março de 2010

\section{Resumo}

Este trabalho estuda a interação entre a regulação jurídica e o conceito de empreendedorismo, analisando seu significado institucional, e verificando o impacto de sua aplicação como argumento no caso "Actium", do setor de telecomunicações. O caso se refere a pedido de autorização para prestação de serviço de telecomunicações, indeferido pela Agência Nacional de Telecomunicações por ausência de previsão regulatória. $\mathrm{O}$ estudo segue este roteiro: na primeira parte, demonstra-se que a variação na regulação jurídica sobre determinada atividade é determinada pelo grau de concentração regulatória, normativa e operacional, a ela aplicável. $\mathrm{O}$ conceito trabalhado por Herren Aguillar se refere à interpretação da atividade regulatória do Estado como um espectro de possibilidades de atuação, que oscila entre a abertura de espaços à iniciativa privada e a intervenção estatal. Na segunda parte, são apresentados os elementos funcionais do fenômeno do empreendedorismo, sistematizados por Michael Peneder, relacionando-o à assunção de risco, coordenação de mercado, difusão tecnológica, inovação, bem como é demonstrada sua relevância jurídica, em conexão com os princípios da livre iniciativa e livre concorrência. Em seguida, os fatos relevantes do caso "Actium" são descritos, e é implementada a análise das consequências jurídicas da aplicação do conceito de empreendedorismo ao caso, com destaque para a conformação do significado do princípio da isonomia no contexto. Por fim, o trabalho conclui que o conceito de empreendedorismo é juridicamente relevante, e sua aplicação pode produzir impacto no debate sobre o grau de concentração regulatória normativa aplicável à prestação de determinado serviço de telecomunicações.

*Uma versão anterior deste artigo foi aprovada para apresentação na $4^{\text {a }}$ Conferência Internacional da Acorn-Redecom, de 14 e 15 de maio de 2010. Acesso em: www.acornredecom.org.

${ }^{* *}$ Assessor da Secretaria de Assuntos Estratégicos da Presidência da República. Pesquisador do Grupo de Estudos em Direito das Telecomunicações da UnB. 


\section{Abstract}

This work addresses the interaction between legal regulation and the concept of entrepreneurship by analyzing its institutional meaning and verifying the impact of its use as a reason in a case from the telecommunication sector, the so-called "Actium" case. The case refers to a request for authorization to provide a telecommunication service, rejected by the National Telecommunications Agency as it ruled there was no regulatory support for that purpose. This article is divided in four topics: in the first part, we demonstrate that the legal regulation for a certain activity varies according to the applicable level of normative and operational regulatory concentration. This concept presented by Herren Aguillar refers to the interpretation of the State regulatory activity as a spectrum of possible ways of acting, varying between opening normative spheres to private actors and State intervention. In the second part, the functional elements of the entrepreneurial phenomenon as organized by Michael Peneder are presented, and connected to risk bearing, market coordination, technology diffusion, innovation and so forth. We demonstrate they are legally relevant as related to freedom of trade and commerce and competition law principles. Then, we describe the relevant facts of the "Actium" case, and analyze the legal consequences of using the concept of entrepreneurship to the case, especially to the meaning of the equal protection of law in this context. Finally, we conclude that the concept of entrepreneurship is legally relevant, and its use may impact the level of normative regulatory concentration applicable to a given telecommunication service.

Palavras-chave: empreendedorismo; livre iniciativa; livre concorrência; caso Actium; Brasil. Keywords: entrepreneurship; freedom of trade; competition law; Actium case; Brazil.

\section{Introdução}

O objetivo do trabalho é entender a relação entre a regulação jurídica e o conceito de empreendedorismo, avaliando a possibilidade e relevância jurídica de sua aplicação em um caso do setor de telecomunicações. Para tanto, foi selecionado o caso "Actium", que diz respeito a um pedido de outorga de autorização para prestação em caráter secundário do serviço de telecomunicações denominado Serviço Móvel Especializado (“SME”), em faixa originariamente destinada ao Serviço Móvel Pessoal ("SMP”). No caso, a Agência Nacional de Telecomunicações (ANATEL) indeferiu o pedido, por ausência de previsão regulatória. $\mathrm{O}$ trabalho discute $\mathrm{o}$ 
fundamento da decisão da ANATEL, levando em consideração a relação possível entre a regulação jurídica e o conceito de empreendedorismo.

\section{Regulação jurídica e o conceito de gradação da concentração regulatória}

Regulação jurídica significa tanto interferência estatal quanto abertura de espaços normativos, em que a conformação do setor de telecomunicações depende de opções dos atores envolvidos. Ao se abrir o referido espaço, o problema que se enfrenta é o de se detectar guias normativos que justifiquem a ausência de normatização expressa para o setor regulado. A importância dessa abordagem para o presente estudo está em que o conceito jurídico de empreendedorismo pode ser cogitado como um dos guias normativos capazes de dimensionar o grau de interferência estatal no setor regulado, bem como interferir na definição da interpretação adequada do sistema regulatório em vigor.

Herren Aguillar considera a regulação jurídica como uma política pública de atribuição de prerrogativas aos agentes de um setor, sejam eles privados ou estatais. ${ }^{1}$ Estas prerrogativas podem ter caráter tanto de atribuição positiva de funções e obrigações quanto de reserva de espaços de liberdade de atuação, que correspondem a visões de mundo com ênfase reguladora ou desreguladora, respectivamente. Estas visões de mundo são usualmente vistas como irreconciliáveis. ${ }^{2}$

${ }^{1}$ HERREN AGUILLAR, Fernando. Controle social de serviços públicos. São Paulo: Max Limonad, 1999. p. 29-30.

${ }^{2}$ Segundo Carlos Ari Sundfeld, haveria uma oposição entre visões irreconciliáveis de regulação de serviços públicos, que nomeamos de visão reguladora, ou estatista, e desreguladora, ou liberal: "Para além dos aspectos mais pontuais da controvérsia sobre a validade ou não do novo conceito de serviço público da LGT, há sim uma oposição irreconciliável de visões sobre regulação. Os arautos do serviço público fechado como modelo único crêem que os poderes do regulador devem ser sempre totais e fracos os direitos dos regulados. Já os que admitem no serviço público o sistema de regulações assimétricas entendem necessária a gradação daqueles poderes e direitos, conforme a classe de prestadores e os interesses públicos realmente envolvidos. A primeira visão mais estatista, a segunda mais liberal" (SUNDFELD, Carlos Ari. Meu depoimento e avaliação sobre a Lei Geral de Telecomunicações. In: Revista de Direito de Informática e Telecomunicações, v. 2, 2007. p. 65). 
A oposição entre regulação e desregulação pode ser mitigada por meio do conceito de gradação da concentração regulatória. Herren Aguillar utiliza este conceito para afirmar que, ao invés de uma oposição entre pólos bem definidos, há um espectro de possibilidades de proporção entre o papel do Estado e o da iniciativa privada - proporção esta sempre mediada por uma escolha estatal. Nas palavras do autor, "toda liberdade de empreender de que desfrute a iniciativa privada em relação ao Estado é, conquanto paradoxalmente, consequência de uma política regulatória estatal, uma política de regulação pela desconcentração"3.

Os espaços de liberdade a que nos referimos podem ser caracterizados ou pela liberdade de atuar diretamente na prestação do serviço, ou pela liberdade de definir as regras sob as quais o serviço é prestado. Essa caracterização dos espaços de liberdade corresponde à natureza operacional $^{4}$ ou normativa ${ }^{5}$, respectivamente, da concentração regulatória que os define.

O autor entende que a satisfação do interesse público pela iniciativa privada serve de guia para a confiança do Estado, que repercute no grau de concentração regulatória tanto operacional quanto normativa. ${ }^{6}$ Em outras palavras, o interesse público é o critério que determina a medida do grau de concentração regulatória devido a dada atividade. De fato, a supremacia do interesse público é o fundamento da ação administrativa, e da própria normatização de setores da economia e da vida em sociedade, em sua relação com o Estado. ${ }^{7}$

Ao contrário de identificarmos automaticamente o interesse público com o conteúdo da lei, entendemos que o interesse público é "elo de mediação de

${ }^{3}$ HERREN AGUILLAR, Fernando. Controle social de serviços públicos. São Paulo: Max Limonad, 1999. p. 211.

${ }^{4}$ Sobre 0 conceito de regulação operacional: "A regulação operacional é manifestada pela preferência outorgada à iniciativa privada ou às empresas e órgãos estaduais para o desempenho de certas atividades de interesse público". Ibidem. p. 164.

5Sobre 0 conceito de regulação normativa: "Já a regulação normativa diz respeito ao poder de regulamentar efetivamente o setor que interesse ao Estado". Ibidem. p. 164.

'Ibidem. p. 164.

${ }^{7}$ Isto fica claro no seguinte trecho: “(...) o interesse público é sempre determinante do perfil regulatório dos serviços públicos. É o interesse público que determina o grau de concentração regulatória (...)". Ibidem. p. 163.

Revista de Direito, Estado e Telecomunicações, v. 2, n. 1, p. 161-188 (2010)

DOI: https://doi.org/10.26512/lstr.v2i1.21686 
interesses privados dotados de legitimidade" 8 . Em face da diversidade de valores e interesses amparados pela lei, a complexidade da definição de interesse público torna sua conformação possível não em abstrato, mas somente a cada aplicação:

Ora, a idéia de que 0 interesse público seria aquele prescrito na lei acarretava, necessariamente, a idéia de existência de um - e apenas um interesse público primário. Porém, ocorre que - conforme leciona Alessandro Pizzorusso - "o que se encontra na vida real são os múltiplos e diversos interesses públicos, enquanto o interesse público no singular é apenas uma locutio brevis para indicar qual o interesse público em si dentre aqueles que será aquele que deva ser consagrado no caso concreto".

Assim, se o interesse público é o critério que define o grau de concentração regulatória normativa, não é um critério uniforme, nem para todos os setores regulados, nem dentro dos próprios setores. ${ }^{10}$ Naturalmente isto gerará diferentes graus de concentração regulatória. Além disso, pode-se radicalizar a assunção da complexidade do interesse público, admitindo sua definição no caso concreto. Isto ocorre em um processo de mediação de interesses, todos legitimados factual e juridicamente, ou seja, fundamentados em demandas sociais e em princípios do ordenamento jurídico. Em última análise, a definição do grau de concentração regulatória em um dado caso deve levar em conta todos os interesses assim caracterizados - sejam especiais, conectados a grupos sociais identificáveis, sejam difusos, sem essa correspondência clara no corpo social.

A partir deste quadro, a abertura de espaço normativo para a prestação de serviços públicos pela iniciativa privada pode ser justificada pela consideração estatal de um interesse fundado em um conceito juridicamente

${ }^{8}$ MARQUES NETO, Floriano Peixoto de Azevedo. Regulação estatal e interesses públicos. São Paulo: Malheiros, 2002. p. 149.

${ }^{9}$ Ibidem. p. 156.

${ }^{10}$ Segundo Floriano Marques: "Decorre daí a noção de que a homogeneidade do interesse público tem que dar lugar à idéia de heterogeneidade de interesses públicos. Nas palavras de Giannini, "hoje a realidade nos mostra que também os interesses da esfera pública são heterogêneos"'. Ibidem. p. 151.

Revista de Direito, Estado e Telecomunicações, v. 2, n. 1, p. 161-188 (2010)

DOI: https://doi.org/10.26512/lstr.v2i1.21686 
relevante ${ }^{11}$, em jogo com outros interesses. É assim que a abordagem do conceito jurídico de empreendedorismo se faz importante como argumento para a justificação de relativa desconcentração regulatória normativa na regulação de determinada atividade. Caso esta justificação se confirme em abstrato, poderemos proceder à sua avaliação em face de um caso concreto, e verificar se o referido conceito produz efeitos juridicamente relevantes na interpretação da regulamentação em vigor.

\section{Empreendedorismo: elementos funcionais do fenômeno e seu apoio jurídico}

As definições de empreendedorismo são muito variadas na literatura. ${ }^{12}$ Michael Peneder indica dois fatores que a influenciam. ${ }^{13} \mathrm{O}$ primeiro fator consiste em não haver consenso sobre as funções essenciais que são imputadas ao empreendedorismo. Segundo o autor acima citado, a literatura sugere que o fenômeno é responsável ao mesmo tempo tanto pelo movimento do sistema econômico em direção ao equilíbrio como pela geração de desequilíbrio no mercado. Isto é, a depender da corrente de pensamento, o empreendedorismo é fator que aumenta a eficiência alocativa para dados meios e fins, ou dinamiza a atividade econômica pela criação progressiva de novos produtos, serviços, processos ou mercados. ${ }^{14}$

Em segundo lugar, a variedade de conceitos se deve à natureza interdisciplinar do tema, envolvendo estudiosos dos campos de economia, administração, sociologia e psicologia, não raro com linhas divergentes em cada um desses campos. ${ }^{15}$ Há uma tendência de o conceito de

${ }^{11} \mathrm{~A}$ demanda social como critério de legitimidade é sempre aferida no caso concreto, e pode ser dada como existente sempre que a resposta estatal se der mediante provocação pelo particular, dado que a provocação do Estado é a própria manifestação da demanda social.

${ }^{12} \mathrm{HÉBERT}$, Robert F.; LINK, Albert N. In the search of the meaning of entrepreneurship. In:

Small Business Economics. Vol. 1, n. 1, 1989. p. 41.

${ }^{13}$ PENEDER, Michael R. The Meaning of Entrepreneurship: Towards a Modular Concept. In:

WIFO Working Papers, n. 335. Viena: WIFO, Março de 2009. p. 2. Disponível em: http://www.wifo.ac.at/wwa/servlet/wwa.upload.DownloadServlet/bdoc/WP_2009_335\$.PDF.

Acesso em: 23 mar 2010.

${ }^{14}$ Ibidem.

${ }^{15}$ Ibidem.

Revista de Direito, Estado e Telecomunicações, v. 2, n. 1, p. 161-188 (2010)

DOI: https://doi.org/10.26512/lstr.v2i1.21686 
empreendedorismo refletir o aspecto do fenômeno que é mais caro aos interesses de estudo próprios de cada área. Como Peneder explica, o economista em geral está preocupado em entender o funcionamento do sistema econômico e, por isso, tem a tendência de caracterizar o empreendedorismo pelas funções particulares que exerce no desenvolvimento da economia. Administradores dão ênfase ao aspecto comportamental, interessados em como agir de maneira empreendedora, enquanto sociólogos voltam-se para a explicação da influência social no comportamento empreendedor. $\mathrm{E}$ assim por diante.

Seguindo os passos da análise de Michael Peneder ${ }^{16}$, podem ser destacadas sete correntes teóricas que enfatizam a função que $o$ empreendedorismo exerce na economia. ${ }^{17}$ Nelas, a figura do indivíduo empreendedor exerce a função de: (i) dono de um negócio; (ii) assunção de risco; (iii) coordenação de mercado; (iv) inovação; (v) difusão de tecnologias; (vi) rent-seeking ${ }^{18}$; e (vii) empreendedor corporativo.

Embora seja comum que cada corrente contenha divisões internas, de acordo com peculiaridades do pensamento dos vários autores que a compõem, uma descrição simplificada do significado de cada uma é útil para entendermos a eventual pertinência de um conceito jurídico de empreendedorismo. Em primeiro lugar, o empreendedor como dono de um negócio é visto como um gerente especializado na coordenação do trabalho de outros empregados ${ }^{19}$, ou na tomada de decisões valorativas sobre a

${ }^{16}$ Ibidem. p. 4-13.

${ }^{17} \mathrm{O}$ aspecto funcional foi destacado considerando que 0 Direito tem a função social dos fenômenos em grande conta no processo de atribuição de significado aos seus conceitos e princípios. Dentre as funções sociais, a função econômica foi enfatizada por sua preponderância no processo de decisão estatal sobre o modo de regular o setor de telecomunicações, foco deste trabalho.

${ }^{18} \mathrm{O}$ termo se refere a atividades que desperdiçam recursos praticadas por indivíduos e grupos que buscam transferência de riquezas. Em outras palavras, são atividades não-produtivas que geram riqueza para quem as pratica, em detrimento da sociedade. "There is an increasing use of the concept of rent seeking to describe resource-wasting actitivies for individuals and groups seeking wealth transfers" (PASOUR, JR., E. C. Rent Seeking: Some Conceptual Problems and Implications. In: The Review of Austrian Economics. Vol. 1, n. 1, 1987. p. 123. Disponível em: http://mises.org/journals/rae/pdf/rae1 1 8.pdf. Acesso em: 23 mar 2010).

${ }^{19}$ MARSHALL, Alfred. Principles of Economics. New York: Cosimo, 2009. p. 244.

Revista de Direito, Estado e Telecomunicações, v. 2, n. 1, p. 161-188 (2010) 
coordenação de recursos escassos ${ }^{20}$. Embora seja claro que a atividade empreendedora abrange esse aspecto, a maioria dos economistas não recebe bem a restrição do empreendedorismo ao gerenciamento puro. ${ }^{21}$

Outros autores entendem que a característica própria da atividade empreendedora é a assunção de risco, ou de incerteza. ${ }^{22}$ Cantillon identifica que certos agentes contratam fornecedores e trabalhadores a um preço determinado para fabricar produtos que serão vendidos a um preço incerto. ${ }^{23}$ Essa incerteza que o empreendedor assume seria o fundamento do seu lucro. No processo histórico de especialização da produção, os chamados empreendedores assumiriam o controle e a responsabilidade pelo processo produtivo e arcariam com o risco intrínseco à atividade, enquanto os empregados inserir-se-iam na produção sem arcar com o risco pelo resultado. Por isso, para Frank Knight, suportar o risco do empreendimento é o caráter distintivo do empreendedor. ${ }^{24}$

A terceira abordagem é aquela que valoriza o empreendedorismo como processo de coordenação de mercado. Isto é, como o processo de identificação de oportunidades lucrativas no mercado. Hayek, em especial, explica que o processo competitivo estimula a descoberta de oportunidades de lucro através da informação revelada no movimento do sistema de preços. ${ }^{25} \mathrm{O}$ empreendedor seria um agente intermediário, alerta às oportunidades de acoplar custos baixos, do lado dos fornecedores, a receitas altas, do lado dos clientes. ${ }^{26}$ No decorrer do tempo, o resultado do processo de coordenação de mercado é o equilíbrio entre oferta e demanda de produtos e serviços - ou estabilidade alocativa.

${ }^{20} \mathrm{CASSON}$, Mark. The entrepreneur: an economic theory. $2^{\mathrm{a}}$ ed. Cheltenham, UK: Edward Elgar Publishing, 2003. p. 20.

${ }^{21}$ PENEDER, Michael R. Op. cit., p. 6.

${ }^{22}$ Ibidem.

${ }^{23}$ CANTILLON, Richard. Essays on the nature of commerce in general. New Brunswick, New Jersey: Transaction Publishers, 2001. p. 25.

${ }^{24}$ KNIGHT, Frank Hyneman. Risk, uncertainty and profit. New York, NY: Cosimo, 2005. p. 271

${ }^{25}$ HAYEK, F.A. The use of knowledge in society. In: American Economic Review. Vol. 35, n. 4, setembro, 1945. p. 526.

${ }^{26} \mathrm{KIRZNER}$, Israel M. Competition and Entrepreneurship. Chicago: University of Chicago Press, 1973. p. 48.

Revista de Direito, Estado e Telecomunicações, v. 2, n. 1, p. 161-188 (2010)

DOI: https://doi.org/10.26512/lstr.v2i1.21686 
Em sentido contrário, Schumpeter admite a criação de oportunidades - e correspondente instabilidade econômica - como parte da dinâmica do mercado. A criação de oportunidades se dá pela implementação de combinações inovadoras dos fatores de produção: o fator distintivo dos empreendedores. O empreendedor é o que realiza, implementa comercialmente uma ideia inédita, e trabalha em conjunto com outros agentes no processo produtivo. Por sua clareza, é merecedora de citação a sistematização de Erik Stam dos diferentes papéis propostos por Schumpeter:

Schumpeter distingue quatro papéis no processo de inovação: 0 inventor, quem inventa uma ideia nova; 0 empreendedor, quem comercializa essa nova ideia; o capitalista, quem fornece os recursos financeiros ao empreendedor (e suporta o risco do projeto de inovação); 0 gerente, quem cuida da rotina diária da gestão corporativa. ${ }^{27}$

A quinta corrente intelectual tem o mérito de enfatizar um processo que se serve, em alguma medida, da inovação e da coordenação de mercado, tratadas acima: a difusão tecnológica. ${ }^{28} \mathrm{O}$ empreendedor atuaria para difundir na sociedade os benefícios dos avanços tecnológicos produzidos por pesquisa universitária, por exemplo. Ocorreria um processo de imitação da tecnologia adotada em uma aplicação ou mercado, com sua transferência para outras aplicações ou mercados. Por um lado, a tecnologia em si produz instabilidade econômica ao representar uma inovação; por outro, a transferência da tecnologia a um novo mercado ou aplicação é parte de um processo de coordenação de oferta e demanda.

A penúltima linha teórica se refere ao comportamento de busca e exploração de oportunidades lucrativas, independentemente de serem relacionadas ou não à inovação, ou mesmo de se traduzirem em prejuízo à sociedade. William Baumol é representativo da identificação do chamado rent-seeking com o empreendedorismo. Ele formula uma definição de

${ }^{27}$ STAM, Erik. Entrepreneurship and Innovation. In: STAM, Erik; NOOTEBOOM, Bart (eds.). Micro-Foundations for Innovation Policy. Amsterdam: Amsterdam University Press, 2008. p. 135.

${ }^{28}$ PENEDER, Michael R. Op. cit., p. 10-11.

Revista de Direito, Estado e Telecomunicações, v. 2, n. 1, p. 161-188 (2010) 
empreendedorismo que não incorpora o aspecto valorativo positivo geralmente associado ao fenômeno, consubstanciando-se no que denomina de empreendedorismo improdutivo. Admitindo que o empreendedorismo pode gerar ou não benefício social, propõe como problema a alocação dos recursos empreendedores em atividades produtivas, e a formulação de políticas públicas correspondentes, que promovam a alocação eficiente de tais recursos. ${ }^{29}$

A última linha teórica de nossa exposição é a linha do empreendedorismo corporativo. O foco desta linha é a determinação do locus do empreendedorismo ${ }^{30}$, tanto para saber se o empreendedorismo é uma característica permanente ou temporária em uma corporação ou indivíduo, como para identificar a dinâmica do empreendedorismo em pequenas ou grandes empresas.

Esse é o quadro das linhas teóricas que se pretendia expor, a partir do qual resta clara a variedade de conteúdo imputado ao conceito de empreendedorismo. Frente a esse quadro, pode-se citar uma tentativa de aglutinação dos diversos significados de empreendedorismo em um só conceito. Embora seja válido questionar sua capacidade de descrição da complexidade do fenômeno, esta solução tem o mérito de sintetizar em um mesmo contexto grande parte dos temas tratados acima. Abaixo, um exemplo de conceito produto da referida aglutinação:

Empreendedorismo se refere à habilidade e vontade manifesta de indivíduos, por si próprios, ou em grupos, dentro e fora de organizações preexistentes, de perceber e criar novas oportunidades econômicas (novos produtos, novos métodos de produção, novos modelos organizacionais e novas combinações produto-mercado), e introduzir suas ideias no mercado, enfrentando incerteza e outros obstáculos, e fazendo decisões sobre a alocação, forma e uso de recursos e

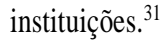

${ }^{29}$ BAUMOL, William J. Entrepreneurship: productive, unproductive, and destructive. In: Journal of Political Economy, Vol. 98, n. 5, 1990. p. 897-898.

${ }^{30}$ PENEDER, Michael R. Op. cit., p. 12.

${ }^{31}$ WENNEKERS, Sander; THURIK, Roy A. Linking Entrepreneurship and Economic Growth. In: Small Business Economics, Vol. 13, 1999. p. 46-47.

Revista de Direito, Estado e Telecomunicações, v. 2, n. 1, p. 161-188 (2010)

DOI: https://doi.org/10.26512/lstr.v2i1.21686 
De qualquer forma, mesmo temas tão diferentes entre si quanto administração de recursos, propensão ao risco, difusão tecnológica, equacionamento de oferta e demanda do mercado e inovação contêm uma linha comum, que lhes dá ossatura jurídica: a liberdade, aqui entendida como espaço normativo de abertura e proteção à ação do indivíduo em função do risco, da oportunidade, da difusão tecnológica, da inovação, e assim por diante.

Se há relação entre empreendedorismo e liberdade, essa relação, para ser jurídica, tem que partir dos componentes institucionais do princípio jurídico tradicionalmente aceito e, ele sim, poderá ser melhor compreendido por um seu componente institucional - uma sua garantia institucional em termos schmittianos), que revele mais uma dimensão obscurecida pela ausência da referência ao conceito de empreendedorismo. Um instituto é um componente cultural que influencia e é influenciado por significados adjacentes. Assim, a liberdade jurídica tem reforço em conceitos ou outras cristalizações culturais institucionais, no caso o empreendedorismo como instituto jurídico aglutinador de enunciados normativos reconhecidos no ordenamento.

O que se procura é a relação principiológica de reforço recíproco entre liberdade jurídica e as dimensões institucionais - as manifestações jurídicas do conceito de empreendedorismo. Dimensões conceituais do empreendedorismo, não o seu significado integral, poderão ser detectadas em dispositivos que servirão, em conjunto com a dimensão maior conceitual de empreendedorismo, como apoio institucional à liberdade.

O componente principal do empreendedorismo, em sua expressão jurídica, é a livre iniciativa. A livre iniciativa é mencionada no texto constitucional como fundamento da República Federativa do Brasil (art. $1^{\circ}$, $\mathrm{IV}^{32}$ ) e como fundamento da ordem econômica (art. 170, caput $^{33}$ ). Em relação à livre iniciativa como fundamento da República, Eros Grau ressalta

${ }^{32}$ Conforme: "Art. $1^{0}$ A República Federativa do Brasil, formada pela união indissolúvel dos Estados e Municípios e do Distrito Federal, constitui-se em Estado Democrático de Direito e tem como fundamentos: (...) IV - os valores sociais do trabalho e da livre iniciativa;".

${ }^{33}$ Conforme: "Art. 170. A ordem econômica, fundada na valorização do trabalho humano e na livre iniciativa, tem por fim assegurar a todos existência digna, conforme os ditames da justiça social, observados os seguintes princípios: (...)”. 
que o valor social a que se refere a Constituição se aplica tanto ao trabalho, em sentido restrito, quanto à livre iniciativa.

Isso significa que a livre iniciativa não é tomada, enquanto fundamento da República Federativa do Brasil, como expressão individualista, mas sim no quanto expressa de socialmente valioso. ${ }^{34}$

$\mathrm{Na}$ medida em que produz riqueza, a livre iniciativa tem valor social, e compõe o trabalho humano enquanto fundamento do Estado brasileiro:

É que a livre iniciativa é um modo de expressão do trabalho e, por isso mesmo, corolária da valorização do trabalho, do trabalho livre como observa Miguel Reale Júnior - em uma sociedade livre e pluralista. ${ }^{35}$

Uma série de significados específicos podem ser vinculados à livre iniciativa $^{36}$, classificados como liberdades públicas ou privadas, conforme a natureza da relação, com o Estado ou outros particulares. A primeira categoria é a livre iniciativa como: (i) liberdade de comércio e indústria (ausência de ingerência do Estado no domínio econômico), seja (i.1) faculdade de criar e explorar uma atividade econômica a título privado (liberdade pública), ou (i.2) não sujeição a qualquer restrição estatal senão em virtude de lei (liberdade pública). É a este significado que muitas vezes se referem os autores quando tratam da livre iniciativa. Aqui, o ponto fundamental é a liberdade de iniciativa econômica, em especial a liberdade de empresa. A segunda categoria de significados específicos é a livre iniciativa enquanto livre concorrência, que será tratada adiante.

Celso Ribeiro Bastos entende que a livre iniciativa, neste sentido, deveria ser considerada como direito fundamental ${ }^{37}$, conforme segue:

$\mathrm{Na}$ verdade esta liberdade é uma manifestação dos direitos fundamentais e no rol daqueles devia estar incluída. De fato o homem não pode realizar-se plenamente enquanto não lhe for dado 0 direito de

\footnotetext{
${ }^{34} \mathrm{GRAU}$, Eros Roberto. A ordem econômica na constituição de 1988. $11^{\mathrm{a}}$ ed. São Paulo: Malheiros, 2006. p. 200.

${ }^{35}$ Ibidem. p. 206.

${ }^{36}$ Ibidem. p. 204.

${ }^{37}$ Contra a livre iniciativa como direito fundamental, ver: GRAU, Eros Roberto. Op. cit., p. 207.

Revista de Direito, Estado e Telecomunicações, v. 2, n. 1, p. 161-188 (2010)

DOI: https://doi.org/10.26512/lstr.v2i1.21686
} 
projetar-se através de uma realização transpessoal, vale dizer, por meio da organização de outros homens com vistas à realização de um objetivo. Aqui a liberdade de iniciativa tem conotação econômica. Equivale dizer ao direito que todos têm de lançarem-se ao mercado da produção de bens e serviços por sua conta e risco. Aliás, os autores reconhecem que a liberdade de iniciar a atividade econômica implica a de gestão e a de empresa.

A liberdade de iniciativa e de empresa pressupõe o direito de propriedade da mesma forma que é de certa forma uma decorrência deste. 0 seu exercício envolve uma liberdade de mercado, o que significa dizer que são proibidos os processos tendentes a tabelar os preços ou mesmo forçar a venda em condições que não sejam as resultantes do mercado. A liberdade de iniciativa exclui a possibilidade de um planejamento vinculante. $O$ empresário deve ser o senhor absoluto na determinação do que deve produzir, como produzir, e por que preço vender. Esta liberdade, como todas as outras de resto, não pode ser exercida de forma absoluta. Há necessidade sim de alguns temperamentos. 0 importante, contudo, é notar que a regra é a liberdade. Qualquer restrição a esta há de decorrer da própria Constituição ou de leis editadas com fundamento nela. ${ }^{38}$ (grifos nossos)

O significado de livre iniciativa, no que se refere à prestação de serviços públicos, exige que o Estado não oponha impedimento à liberdade humana no que seja socialmente desejável. ${ }^{39}$ Ora, resta claro a partir dos excertos transcritos que a livre iniciativa, enquanto liberdade de produção, se serve de elementos do conceito de empreendedorismo, especialmente: a capacidade de coordenação de mercado para a satisfação da demanda dos consumidores; a gestão corporativa como organização dos fatores da produção; a assunção do risco e da responsabilidade correspondente. Daí decorre que o empreendedorismo merece ter seu espaço de proteção jurídica, enquanto atividade de realização do homem e socialmente produtiva e que o Estado não restrinja a atividade a não ser quando em conflito com outros interesses públicos, vale dizer, interesses especiais ou

${ }^{38}$ BASTOS, Celso Ribeiro. Comentários à Constituição do Brasil. Vol. 7. São Paulo: Saraiva, 1990. p. 16-17.

${ }^{39} \mathrm{GRAU}$, Eros Roberto. Op. cit., p. 207.

Revista de Direito, Estado e Telecomunicações, v. 2, n. 1, p. 161-188 (2010)

DOI: https://doi.org/10.26512/lstr.v2i1.21686 
difusos legitimados por demandas sociais e princípios estruturantes da ordem jurídica.

Ao conjunto de significados específicos da livre iniciativa, reunidos sob a insígnia da liberdade de comércio e indústria, agrega-se outro conjunto ${ }^{40}$, também dividido em liberdades públicas e privadas, pelo qual a livre iniciativa é vista sob a ótica da: (i) liberdade de concorrência, seja (i.1) faculdade de conquistar a clientela, desde que não através de concorrência desleal (liberdade privada), (i.2) proibição de formas de atuação que deteriam a concorrência (liberdade privada), ou (i.3) neutralidade do Estado diante do fenômeno concorrencial, em igualdade de condições dos concorrentes (liberdade pública). Nela se encontra o segundo pilar do empreendedorismo em sua expressão jurídica, que é a valorização da competição, instrumento de realização do bem-estar dos consumidores e da coletividade como um todo - não só pelos preços baixos que provoca como também pelas inovações que impulsiona.

Vale ressaltar que a livre concorrência resulta em desigualdade de resultados, vencendo o melhor competidor. Entretanto, supõe igualdade de condições no início do jogo. ${ }^{41}$

O comportamento competitivo é a base da procura e exploração de oportunidades característica do empreendedorismo. Ou seja, a livre concorrência desencadeia o comportamento empreendedor. Nesse sentido, pode ser interpretada como um instrumento do ordenamento que leva em conta o empreendedorismo, como um comportamento socialmente desejável. A competitividade é constituída por esse dinamismo de forças, que lutam para sobrepor-se uma à outra no mercado. Existe o pressuposto, entretanto, de que haja igualdade de condições, dado que apenas concorrem entre si os que se encontram em condições comparáveis. Daí a proteção à concorrência, em sentido material, seja como repressão ao abuso do poder econômico, seja como tratamento diferenciado à pequena e média empresa.

Desdobramentos da livre iniciativa e da livre concorrência, ou mesmo os elementos específicos do empreendedorismo, encontram repercussão na

${ }^{40}$ GRAU, Eros Roberto. Op. cit., p. 204.

${ }^{41}$ GRAU, Eros Roberto. Op. cit., p. 209.

Revista de Direito, Estado e Telecomunicações, v. 2, n. 1, p. 161-188 (2010)

DOI: https://doi.org/10.26512/lstr.v2i1.21686 
regulamentação específica do setor de telecomunicações. A esse respeito, merecem destaque os arts. $6^{\circ}, 71,110,127$, I, II e IX, 129, 136, 146, 150 e 155 da Lei 9.472, de 16 de julho de 1997, a Lei Geral de Telecomunicações ("LGT"). Em todos os casos, o empreendedorismo é reforçado como expressão da livre iniciativa, em sentido amplo, e, por sua vez, reforça essa liberdade jurídica, revelando uma dimensão do seu significado.

Definidos os elementos do empreendedorismo e sua relevância jurídica, está confirmada a hipótese de que o conceito de empreendedorismo serve como critério normativo para a determinação do grau de concentração regulatória normativa. $\mathrm{O}$ empreendedorismo requer a liberdade de empresa e a livre concorrência, e realiza o valor social desses institutos, de produção de riqueza e bem-estar, inclusive na prestação de serviços públicos. Isto the dá o caráter de interesse público, enquanto realização dos princípios estruturantes da ordem econômica constitucional. Na classificação de Floriano Peixoto de Azevedo Marques $\mathrm{Neto}^{42}$, seu caráter de interesse público pode ser tanto especial quanto difuso, a depender da presença ou não de grupos de pressão definidos, e da ênfase dada a cada aspecto do fenômeno, enquanto inovação, de interesse manifestamente difuso, ou criação e manutenção de pequenas e médias empresas, um interesse manifestamente especial, por exemplo.

De toda forma, o resultado é a legitimidade do uso do conceito de empreendedorismo para dimensionar a gradação da concentração regulatória normativa: por este critério, via de regra, esta será tão desconcentrada quanto possível, para criar o espaço de liberdade normativa e de ausência regulamentar que possibilita o comportamento empreendedor. Esta consequência da aplicação do conceito de empreendedorismo é cotejada no caso concreto com as consequências de outros interesses públicos, sendo o papel da Administração justamente o de mediar esses interesses. ${ }^{43}$ Pode ocorrer, no entanto, que a consequência da aplicação do conceito seja distinta, e não resulte em abertura de espaço normativo. Como visto, a preservação da concorrência, em sentido material, possibilita o

${ }^{42}$ MARQUES NETO, Floriano Peixoto de Azevedo. Regulação estatal e interesses públicos. São Paulo: Malheiros, 2002. p. 161-162.

${ }^{43}$ MARQUES NETO, Floriano Peixoto de Azevedo. Op. cit., p. 158. 
comportamento empreendedor e demanda concentração regulatória normativa do Estado. Nesse microcosmo, portanto, a consequência é oposta ao apontado acima e, ainda assim, compatível com a preservação das condições institucionais que abrem espaço ao comportamento empreendedor e compõem o significado institucional da liberdade do indivíduo.

Esse significado é construído não só a partir das relações entre o ordenamento e cristalizações culturais, mas também a partir das práticas institucionais que se apóiam e são criticadas por meio de tais relações. Assim, resta-nos analisar, a seguir, a base empírica representativa da prática institucional no setor de telecomunicações e verificar eventuais consequências do quanto foi dito na interpretação da regulamentação em vigor.

\section{Possibilidade de aplicação do conceito de empreendedorismo: o caso "Actium"}

Esta seção pretende demonstrar uma possibilidade de aplicação relevante do conceito de empreendedorismo na interpretação da regulamentação que incide sobre determinado serviço de telecomunicação. A descrição dos fatos relevantes do caso concreto será seguida de análise jurídica da fundamentação da decisão, aproveitando-se o esforço empreendido anteriormente.

O caso diz respeito a pedido de outorga de autorização para prestação do Serviço Móvel Especializado ("SME") ${ }^{44}$ utilizando radiofrequência com destinação em caráter primário ao Serviço Móvel Pessoal (“SMP”). Embora tenha havido sucessivas aprovações dos órgãos envolvidos no processo de autorização, a matéria não foi analisada de pronto pelo Conselho Diretor da ANATEL, que a devolveu ao órgão de origem para mais estudos. Este, por sua vez, indeferiu diretamente o pedido da empresa solicitante, arquivando o

${ }^{44}$ O Serviço Móvel Especializado (SME), também conhecido como trunking ou sistema troncalizado, é um serviço bastante semelhante ao serviço celular. As principais diferenças em relação ao serviço celular no Brasil são: (a) o SME é destinado a pessoas jurídicas ou grupos de pessoas caracterizados pela realização de atividade específica (não pode ser oferecido a pessoas físicas individualmente); e (b) oferece a possibilidade de comunicação tipo despacho (push to talk) para um grupo.

Revista de Direito, Estado e Telecomunicações, v. 2, n. 1, p. 161-188 (2010)

DOI: https://doi.org/10.26512/lstr.v2i1.21686 
processo. Ao final, o Conselho Diretor analisou a matéria, reforçando o despacho de arquivamento. Na ocasião, foi sinalizado que a ANATEL estudaria a possibilidade de editar regulamentação explícita para a hipótese objeto de análise. Este é o argumento principal da decisão: a ausência de regulamentação explícita da hipótese. Admitindo a necessidade de regulamentação explícita da matéria, a decisão nega legitimidade a interpretação possível da regulamentação vigente e não leva em conta as consequências competitivas benéficas do pedido da empresa, ambas reconhecidas pelas áreas técnicas da ANATEL. Abaixo, segue o desenrolar desses fatos, com maior detalhamento.

Em 19 de abril de 2001, a empresa Actium Telecomunicações Ltda. ("Requerente") solicitou autorização para prestação de SME, mediante uso industrial da integralidade da rede de acesso rádio, prescindindo da outorga de autorização de uso de radiofrequência. ${ }^{45} \mathrm{O}$ pedido de autorização foi protocolado sob o n ${ }^{\circ} 53500.002099 / 2002$.

A Gerência Geral de Comunicações Pessoais Terrestres ("PVCP") da Superintendência de Serviços Privados ("SPV"), por meio do Informe no 11 PVCPR/PVCP/SPV, de 19 de fevereiro de 2002, manifestou-se favoravelmente ao pedido da empresa, afirmando que a autorização para prestação do serviço traria "alternativa de competição em um segmento que hoje está, praticamente, monopolizado pela NEXTEL, onde não há alternativa tecnológica nem radiofrequência em condições estruturadas, especialmente nas grandes metrópoles". O documento também ressalta que a agência iria acompanhar com cautela o desenvolvimento do modelo de negócios ${ }^{46}$.

$\mathrm{O}$ processo foi então encaminhado à Procuradoria da ANATEL, que emitiu em 8 de março de 2002 o Parecer no 080/2002-PRC. O parecer esclarece o caráter inovador da solicitação da Requerente, admitindo que, até então, não se havia conferido interpretação à legislação que permitisse a

${ }^{45}$ De acordo com o Informe ${ }^{0} 11$ PVCPR/PVCP/SPV, de 19 de fevereiro de 2002, às fls. 190 dos autos do Processo ANATEL n 53500.002099/2002: "4.27 Na exploração industrial, a prestadora interessada contrata serviços (conforme Decreto 2.197/97) de outra prestadora para prestar o seu próprio serviço. No caso da Actium Telecomunicações, há pretensão de fazer uso da radiofrequência de uma outra prestadora de outro serviço (SMP) [Serviço Móvel Pessoal]". ${ }^{46}$ Fls. 191-193 dos autos do Processo ANATEL n 53500.002099/2002. 
implementação de um serviço móvel mediante uso industrial da integralidade da rede de acesso rádio. De qualquer maneira, o parecer entende pela legalidade da nova interpretação. ${ }^{47}$

A viabilidade jurídica do pleito da Requerente foi atestada ainda pelo Parecer $n^{\circ}$ 394/2002-PGF/PF-ADTB/ANATEL, emitido em 30 de setembro de 2002, e na Matéria para Apreciação do Conselho Diretor $n^{\circ}$ 98, de 8 de maio de 2002. Esta última sugere um acompanhamento dos efeitos da prestação do serviço sob essa modalidade, como seria natural, enfatizando que o incremento à competição é o fator relevante para a autorização do serviço:

3.24 Algumas considerações devem ser explicitadas nas novas autorizações de serviço de telecomunicações de interesse coletivo sem a outorga de Autorização para o Uso da Radiofrequência Associada:

- considerar limites de usuários para acompanhamento pela ANATEL da evolução do serviço;

- autorizar serviços quando isto traduzir incremento à competição no setor desejado;

- $\quad$ analisar caso-a-caso cada solicitação, principalmente com relação ao impacto na competição, considerando para a decisão o Art. 136 da LGT: não haverá limite ao número de autorizações de serviço, salvo em caso de impossibilidade técnica ou, excepcionalmente, quando o excesso de competidores puder comprometer a prestação de uma modalidade de serviço de interesse coletivo. ${ }^{48}$

Entretanto, mesmo estando devidamente instruído para análise final pelo Conselho Diretor da ANATEL, este não se pronunciou formalmente. Foi juntada aos autos nova manifestação da PVCP (Informe $\mathrm{n}^{\circ} 58$, de 18 de setembro de $2002^{49}$ ), na qual são oferecidas duas alternativas para escolha pelo Conselho Diretor ${ }^{50}$ : a primeira, a aprovação imediata do pleito da Requerente, outorgando-lhe autorização com eficácia condicionada à apresentação de contrato particular de uso industrial de meios (item 4.5.1); a

\footnotetext{
${ }^{47}$ Fls. 197-198 dos autos do Processo ANATEL n ${ }^{0} 53500.002099 / 2002$.

${ }^{48}$ Fls. 237 dos autos do Processo ANATEL n ${ }^{0} 53500.002099 / 2002$.

${ }^{49}$ Fls. 239 a 244 dos autos do Processo ANATEL n ${ }^{\circ} 3500.002099 / 2002$.

${ }^{50}$ Fls. 240 dos autos do Processo ANATEL no 53500.002099/2002.

Revista de Direito, Estado e Telecomunicações, v. 2, n. 1, p. 161-188 (2010)

DOI: https://doi.org/10.26512/lstr.v2i1.21686
} 
segunda, submeter norma específica à consulta pública para regular a matéria (item 4.5.2). Com isso, o Conselho Diretor encaminha os autos ao órgão de origem, para realização de mais estudos a respeito do enquadramento regulatório do pedido da Requerente.

O passo seguinte é o arquivamento do pedido pela Gerência de Regulamentação ("PVCPR"), órgão vinculado à PVCP e à SPV, em que a argumentação se baseia na impossibilidade de enquadramento jurídico do pedido da Actium na regulamentação vigente. Após interposição de recurso, o Conselho Diretor se manifesta, em decisão da qual se destaca o seguinte trecho:

Assim, a solicitação da Actium é para um serviço que não existe, pois um SME sem radiofrequências é uma contradição dos próprios termos.

Cabe sempre lembrar que a Administração Pública só pode fazer 0 que a lei e a regulamentação permitem e é uma obrigação da ANATEL 0 respeito às normas administrativas, especialmente àquelas por ela mesma editadas, cujos preceitos não podem ser descumpridos nem mesmo por acordo ou vontade conjunta de seus aplicadores e destinatários, uma vez que contém verdadeiros poderes-deveres, irrelegáveis pelos agentes públicos.

Ademais, a interpretação das normas relativas a telecomunicações é de competência da ANATEL que, exercendo este poder-dever visando 0 interesse público, impede que o sentido da regulamentação dos serviços que fiscaliza seja distorcido, pelas empresas interessadas, de forma a adequá-lo melhor a seus anseios particulares.

(...)

Por último, gostaria de comentar sobre o possível interesse em modificar a regulamentação para permitir a prestação de serviço móvel sem a outorga direta de radiofrequências. A introdução do operador móvel virtual (MVNO - Mobile Virtual Network Operator) parece ser uma boa solução para aumentar a eficiência no uso do espectro e a penetração, principalmente do Serviço Móvel Pessoal - SMP, em cidades de pequeno porte. Tendo em vista o sucesso do MVNO, principalmente nos países escandinavos, a ANATEL deverá estudar as vantagens e desvantagens de tal inovação e, se for o caso, introduzir tal tipo de autorização no arcabouço regulatório brasileiro. ${ }^{51}$

${ }^{51}$ Fls. 460 dos autos do Processo ANATEL n ${ }^{0} 53500.002099 / 2002$. 
Com isso, os autos foram arquivados definitivamente em 21 de março de $2006 . .^{52}$

\section{Análise jurídica do caso Actium}

Passa-se à análise jurídica do caso Actium, acima descrito. Como dito explicitamente no Despacho $\mathrm{n}^{\circ}$ 063/2006-CD, de 6 de fevereiro de 2006, do Conselho Diretor da ANATEL, o fundamento para o indeferimento da outorga de autorização para a prestação do SME é a "impossibilidade do pedido ser enquadrado na regulamentação atual" ${ }^{53}$. Não se pretende discutir o mérito desta afirmação, ou seja, se a ANATEL acertou ou não ao entender que o pedido não se enquadrava na regulamentação, visto que o assunto já foi exaustivamente debatido nos autos. Está demonstrada a incongruência entre diversas manifestações dos órgãos da ANATEL e a decisão do Conselho Diretor, em relação à possibilidade de interpretação da regulamentação vigente em favor da Requerente. Neste ponto, não teríamos inovação a fazer e os autos estão disponíveis para análise de qualquer interessado. $\mathrm{O}$ que se pretende é discutir a própria validade do indeferimento do pedido fundamentado pelo não enquadramento da hipótese na regulamentação vigente.

Em primeiro lugar, e em conformidade com o exposto acima, a livre iniciativa, como expressão do empreendedorismo, impõe que, mesmo na prestação de serviços públicos, a liberdade do indivíduo não seja limitada no que seu exercício seja socialmente desejável. Ou seja, a simples falta de regulamentação explícita não é suficiente para a recusa da outorga da autorização, que precisa ser motivada com base na ocorrência de prejuízo à concorrência, à segurança na prestação do serviço ou em outros fundamentos, visto que a regra é a liberdade de iniciativa, que faz parte do comportamento empreendedor.

No caso, a análise dos órgãos competentes deixa claro nos autos que a implementação da modalidade da prestação do serviço solicitada pela

${ }^{52}$ Fls. 467 dos autos do Processo ANATEL $n^{\circ} 53500.002099 / 2002$.

${ }^{53}$ Fls. 463 dos autos do Processo ANATEL n ${ }^{0} 53500.002099 / 2002$.

Revista de Direito, Estado e Telecomunicações, v. 2, n. 1, p. 161-188 (2010)

DOI: https://doi.org/10.26512/lstr.v2i1.21686 
Requerente é benéfica do ponto de vista competitivo, com possibilidade de contestação da posição de quase monopólio da Nextel $(85 \%$ do mercado à época), uso eficiente do espectro e ampliação da base de usuários. ${ }^{54}$ Como o SME se destina ao mercado corporativo, essa medida tem impactos econômicos significativos, advindos dos ganhos de produtividade gerados pelo uso intensivo de tecnologias da informação e comunicação (TIC).$^{55}$ Além disso, a utilização do modelo proposto pela Actium, de operadora móvel virtual (Mobile Virtual Network Operator - MVNO), foi considerada nos autos como potencialmente eficaz na expansão do serviço para cidades de pequeno porte ${ }^{56}$, argumento que confirma a importância de um modelo não totalmente estranho à prática institucional da ANATEL: o compartilhamento de radiofrequência. No passado, a Telemar pôde implementá-lo, por meio do uso industrial da rede de acesso rádio da Oi para prestar Serviço Telefônico Fixo Comutado (Resolução ANATEL $n^{\circ}$ 278 , de 15 de outubro de 2001). ${ }^{57}$

Tampouco há preocupações legítimas que recomendem observação da agência em relação à segurança na prestação do serviço ao usuário, simplesmente porque não se faria uso inédito da radiofrequência, e sim da integralidade da rede de acesso rádio da empresa prestadora de SMP que, presumivelmente, já operava em total acordo com a regulamentação vigente. A única preocupação regulatória que se justificaria seria com o comportamento do mercado, entretanto, a própria Anatel sugere impor limite de usuários ao serviço como maneira de acompanhar a atividade do modelo. ${ }^{58}$ Sem que se discuta o mérito dessa forma de acompanhamento, o fato é que uma solução para a necessidade de acompanhamento do mercado foi proposta pelos órgãos instrutores da ANATEL em antecipação a eventual preocupação do Conselho Diretor. Essa questão sequer foi levantada em sua decisão.

${ }^{54}$ Fls. 191-192 dos autos do Processo ANATEL n ${ }^{0} 53500.002099 / 2002$.

${ }^{55}$ Fls. 191-192 dos autos do Processo ANATEL no 53500.002099/2002.

${ }^{56} \mathrm{Fls}$. 460 dos autos do Processo ANATEL n ${ }^{0}$ 53500.002099/2002.

${ }^{57} \mathrm{~A}$ informação foi citada em parecer juntado aos autos do Processo ANATEL ${ }^{0}$ 53500.002099/2002, às fls. 358.

${ }^{58}$ Limite sujeito a revisão mediante aprovação pela agência. Fls. 193 e 237 dos autos do Processo ANATEL no 53500.002099/2002. 
Pode-se inferir também que, a partir do Informe $\mathrm{n}^{\circ} 58$ PVCPR/PVCP/SPV, de 18 de setembro de $2002^{59}$, a preocupação com a isonomia levou ao questionamento da alternativa que melhor atenderia o interesse público: autorização da prestação do serviço nos termos em que solicitou a Actium ou realização de estudos para avaliar a proposta de norma que regulamente a matéria explicitamente, a ser submetida a consulta pública. O referido informe argumenta que a consulta pública "assegura a participação de toda a sociedade e oferece a oportunidade a outros interessados no mesmo tipo de solicitação, o que reflete a aplicação do princípio da isonomia, bem como da impessoalidade, uma vez que, a norma aplicar-se-á a todos e não se prestará para atender a uma situação específica"60.

No entanto, viu-se que o interesse público, em sua complexidade, é potencialmente definido apenas no caso concreto, fruto da mediação entre interesses públicos identificados à primeira vista pela Administração. Isto elimina suposta falta necessária ao princípio da isonomia no deferimento de pedido inédito de outorga de autorização para a prestação de serviço de telecomunicações, em hipótese ainda não discutida em consulta pública. $\mathrm{O}$ significado da isonomia deve ser considerado no contexto de outros significados em jogo, entre eles o conceito de empreendedorismo, no que este se relaciona a princípios do ordenamento jurídico.

Já foi dito que a percepção pioneira das oportunidades disponíveis é um elemento constitutivo do empreendedorismo. No caso em análise, a oportunidade percebida pela Actium já estava presente como possibilidade no ordenamento, presumivelmente acessível a todos, uma vez que, conforme nosso entendimento, o princípio da livre iniciativa prescreve a não limitação, de antemão, da iniciativa privada, inclusive na prestação de serviços públicos. Adicionalmente, foi reconhecida no âmbito da ANATEL a legitimidade da interpretação da Actium da possibilidade da prestação do serviço a partir dos elementos existentes na regulamentação vigente também presumivelmente acessível a todos. Assim, no contexto do caso, o

${ }^{59}$ Fls. 239 a 244 dos autos do Processo ANATEL n ${ }^{0} 53500.002099 / 2002$.

${ }^{60}$ Fls. 243 dos autos do Processo ANATEL no 53500.002099/2002.

Revista de Direito, Estado e Telecomunicações, v. 2, n. 1, p. 161-188 (2010)

DOI: https://doi.org/10.26512/lstr.v2i1.21686 
significado da isonomia é a igualdade de condições de acesso à informação necessária para a percepção da oportunidade empreendedora.

Ademais, a própria ANATEL sugere que se faça uma análise caso a caso desse tipo de pedido ${ }^{61}$, e indica que o benefício à competição é um fator a ser levado em consideração para a outorga da autorização em casos semelhantes. Ou seja, a agência reconhece que é possível se fazer a análise caso a caso, e antecipa um elemento importante como argumento nesses casos: o benefício à competição - ainda que em eventual contraposição a um significado possível de igualdade. Por outro lado, a prática institucional da agência mostra que situação semelhante havia sido permitida no passado ${ }^{62}$, presumivelmente em atendimento a interesses legítimos do ponto de vista regulatório. $\mathrm{O}$ mesmo poderia ter ocorrido no caso analisado. Deste modo, a observância da isonomia não é um impedimento à outorga da autorização à Actium, seja porque o significado de isonomia no contexto do caso é de igualdade de acesso às informações relevantes para a percepção da oportunidade, seja porque a própria isonomia pode ser preterida, caso se entenda que outros princípios melhor realizem o interesse público.

A percepção aguçada de oportunidades, como elemento central do empreendedorismo, em seus vários significados, deve ser incentivada não só como decorrência dos benefícios sociais que traz consigo. É que este elemento pode ser identificado como dimensão do significado dos princípios estruturantes de nossa ordem econômica, especialmente a liberdade de iniciativa e de concorrência. $\mathrm{O}$ conceito de empreendedorismo, nesse contexto, serve de unificador de significados na medida em que compatibiliza as consequências aparentemente opostas dos princípios da livre iniciativa e livre concorrência, em sentido material, de abertura de espaços normativos e intervenção na liberdade do particular, proibindo à atividade estatal que diminua a competitividade, ou incentivando aqueles que não têm condições de concorrer em pé de igualdade. O conceito tem o mérito de ressaltar o resultado a que os princípios da livre iniciativa e livre concorrência se vinculam enquanto faces de um mesmo propósito institucional.

${ }^{61}$ Fls. 237 dos autos do Processo ANATEL no 53500.002099/2002.

${ }^{62}$ Ver a Resolução ANATEL n 278, de 15 de outubro de 2001. 


\section{Conclusão}

Como se vê, a aplicação do conceito de empreendedorismo ao caso em tela produz uma alteração radical na interpretação da regulamentação em vigor, dado que não basta que a ANATEL identifique a ausência de regulamentação explícita a respeito de um determinado serviço para que deixe de emitir a correspondente autorização. A regra é a livre iniciativa, expressão do empreendedorismo. É necessário que sejam demonstrados especificamente outros interesses públicos prejudicados pela autorização, para que se faça a necessária mediação, no caso concreto, entre interesses públicos. Portanto, do ponto de vista do argumento do empreendedorismo, a prática institucional da agência reguladora de telecomunicações é questionável, dado que, se levado em consideração, o conceito poderia ter produzido um resultado jurídico diverso, interferindo na gradação da concentração regulatória normativa aplicável à atividade em questão.

Conforme exposto, a regulação jurídica é um fenômeno fluido, que se faz presente na previsão explícita de regras detalhadas para a prestação de um serviço, na aparente omissão normativa, criadora de espaços de liberdade para definição das regras de prestação de um serviço pelo particular, e no continuиm normativo que liga estas duas possibilidades. Cada ponto no referido continuum corresponde ao grau da concentração regulatória normativa aplicável a uma atividade, um serviço específico, ou até mesmo um caso concreto. Defende-se aqui que o instrumento que move o grau de concentração regulatória normativa é a mediação entre interesses públicos realizada pelo Estado, que determina o interesse público para a atividade, o serviço, o caso concreto. Este é o sentido do funcionamento da regulação como gradação da concentração regulatória, fundada no interesse público.

Suposta omissão normativa concretizada em ausência de previsão regulatória explícita não pode servir como argumento suficiente para proibir, no caso, as possibilidades técnicas de prestação de um serviço, uma vez que a regra é a liberdade de iniciativa - uma clara expressão jurídica do empreendedorismo. Ou seja, a liberdade de iniciativa é um fundamento jurídico para a prestação do serviço mediante essas ou aquelas possibilidades técnicas, definidas exclusivamente por aquele que empreende. Esta é uma regra que realiza no caso o propósito institucional de 
fomento ao empreendedorismo, como fonte de produção de riqueza social. Ao mesmo tempo, o empreendedorismo reforça o significado da livre iniciativa, deixando claro quais resultados se espera para a sociedade. Outras relações entre elementos do empreendedorismo e normas jurídicas poderiam ser pensadas, realizando o incentivo à pequena e média empresa, por exemplo. $\mathrm{O}$ importante é o foco no propósito institucional comum às regras: o fomento e proteção jurídicos ao comportamento empreendedor relacionado à inovação, coordenação de demandas do mercado, difusão tecnológica, dentre outros.

Identificada a regra que realiza o propósito institucional mencionado para dada situação (a livre iniciativa, por exemplo), o passo seguinte é a avaliação de outros interesses públicos em jogo. Estes podem reforçar, afastar e modificar as consequências jurídicas da regra, ou assumir um significado específico frente à mesma regra. No caso estudado, o princípio da isonomia assumiu o significado específico de igualdade de acesso às informações necessárias para a percepção da oportunidade empreendedora. Em conjunto com o restante da argumentação construída dentro do caso, esse dado permitiu criticar a prática institucional da Agência Nacional de Telecomunicações, do ponto de vista do empreendedorismo, do incentivo à competição e da isonomia entre os agentes econômicos prestadores do serviço.

Em outras palavras, da exposição conclui-se que o conceito de empreendedorismo é juridicamente relevante para a gradação da concentração regulatória normativa. Sua aplicação, como se observou no caso analisado, pode produzir impacto no debate a respeito do grau de concentração regulatória normativa devido à prestação de determinado serviço de telecomunicações. Com a publicação pela ANATEL de consulta pública com proposta de regulamentação do modelo de operadora virtual de rede $^{63}$ (Mobile Virtual Network Operator - MVNO), desenvolvimentos posteriores da pesquisa podem identificar em que medida o modelo proposto

${ }^{63}$ A Consulta Pública no ${ }^{50}$, lançada em 22 de dezembro de 2009 e encerrada em 22 de março de 2010, propõe o Regulamento sobre exploração de Serviço Móvel Pessoal - SMP por meio de Rede Virtual (RRV-SMP). Ao todo, foram oferecidas 364 contribuições à consulta, cuja análise merece um trabalho à parte. 
pela agência avança em relação aos elementos jurídicos do empreendedorismo, indicando um possível aprendizado institucional da agência sobre o tema. Novos estudos também podem apontar outras expressões jurídicas do empreendedorismo, que se relacionem com o fomento à consolidação de pequenas e médias empresas, por exemplo, bem como em que medida essas expressões se relacionam com princípios de ordem material, como o direito à comunicação e o regime jurídico aplicável ao serviço público.

Entendemos que é a explicitação dessas relações que pode concretizar o que se espera do empreendedorismo, para que se mantenha o foco na produção de riqueza e bem-estar para a sociedade e sejam afastadas iniciativas empreendedoras em um certo sentido, mas improdutivas para o corpo social. Se reconhecemos que o empreendedorismo não é a tábua de salvação para todos os males, queremos entender como a ordem jurídica e a prática de nossas instituições pode detectá-lo, incentivá-lo e direcioná-lo para o que nos pode ser útil.

\section{Bibliografia}

BASTOS, Celso Ribeiro. Comentários à Constituição do Brasil. Vol. 7. São Paulo: Saraiva, 1990.

BAUMOL, William J. Entrepreneurship: productive, unproductive, and destructive. In: Journal of Political Economy, Vol. 98, n. 5, 1990. p. 893921.

CANTILLON, Richard. Essays on the nature of commerce in general. New Brunswick, New Jersey: Transaction Publishers, 2001.

CASSON, Mark. The entrepreneur: an economic theory. $2^{\text {a }}$ ed., Cheltenham, UK: Edward Elgar Publishing, 2003.

GRAU, Eros Roberto. A ordem econômica na constituição de 1988. 11 ${ }^{\text {a }}$ ed. São Paulo: Malheiros, 2006.

HAYEK, F.A. The use of knowledge in society. In: American Economic Review. Vol. 35, n. 4, setembro, 1945. p. 519-530.

HÉBERT, Robert F.; LINK, Albert N. In the search of the meaning of entrepreneurship. In: Small Business Economics. Vol. 1, n. 1, 1989. p. 39-49.

HERREN AGUILlAR, Fernando. Controle social de serviços públicos. São Paulo: Max Limonad, 1999. 
KIRZNER, Israel M. Competition and entrepreneurship. Chicago: University of Chicago Press, 1973.

KNIGHT, Frank Hyneman. Risk, uncertainty and profit. New York: Cosimo, 2005.

MARQUES NETO, Floriano Peixoto de Azevedo. Regulação estatal e interesses públicos. São Paulo: Malheiros, 2002.

MARSHALL, Alfred. Principles of Economics. New York: Cosimo, 2009.

PASOUR, JR., E. C. Rent Seeking: Some Conceptual Problems and Implications. In: The Review of Austrian Economics. Vol. 1, n. 1, 1987. p. 123-143.

PENEDER, Michael R. The meaning of entrepreneurship: towards a modular concept. In: WIFO Working Papers, n. 335. Viena: WIFO, Março de 2009.

STAM, Erik. Entrepreneurship and innovation. In: STAM, Erik; NOOTEBOOM, Bart (eds.). Micro-foundations for innovation policy. Amsterdam: Amsterdam University Press, 2008. p. 135-172.

SUNDFELD, Carlos Ari. Meu depoimento e avaliação sobre a Lei Geral de Telecomunicações. In: Revista de Direito de Informática e Telecomunicações, v. 2, 2007. p. 55-84.

WENNEKERS, Sander; THURIK, Roy A. Linking entrepreneurship and economic growth. In: Small Business Economics, Vol. 13, 1999. p. 27-55. 
